\title{
ANALISIS KOMODITAS UNGGULAN PERIKANAN BUDIDAYA PROVINSI JAWA TENGAH TAHUN 2012-2016 MENGGUNAKAN METODE LOCATION QUOTIENT DAN SHIFT SHARE
}

\author{
Dian Mariana L Manullang ${ }^{1}$, Agus Rusgiyono ${ }^{2}$, Budi Warsito ${ }^{3}$ \\ 1,2,3 Departemen Statistika, Fakultas Sains dan Matematika, Universitas Diponegoro \\ e-mail : agus.rusgi@gmail.com
}

\begin{abstract}
Condition of capture fisheries is currently stagnating, even tended to decline, which is indicated by the decrease of production in some fishery development areas in Indonesia. Aquaculture is one solution that can be done. Central Java Province is a province that has a large aquaculture potential, therefore of course Central Java province has leading commodities that become the sector of regional economic development. This research discusses about the potential location for the development of each leading commodities in Central Java Province as a recommendation related to the centre of fisheries production. Analytical methods in this research are Location Quotient (LQ) dan Shift share. It used to see how big these locations have a potential in the development of aquaculture production and to identify spatial autocorrelation in the amount of aquaculture production using Moran's index. The analysis of LQ and shift share shows that each district has a different potential in the development of leading commodities production. The value of the Moran's index obtained equal to -0.1381 , that is in the range of $-1<\mathrm{I} \leq 0$, indicating that the presence of spatial autocorrelation is negative but small because of near to zero. It can be concluded that there is no similarity of the values between the districts or indicate that amount of aquaculture production among the districts in Central Java are not correlated.
\end{abstract}

Keywords: Leading Commodities, Location Quotient (LQ), Shift Share, Moran's Index

\section{PENDAHULUAN}

Kondisi perikanan tangkap saat ini tengah mengalami stagnasi, bahkan cenderung mengalami penurunan produksi di beberapa wilayah di Indonesia. Degradasi lingkungan perairan laut akibat perubahan iklim global, ditambah lagi dengan eksploitasi ikan yang berlebih tanpa kontrol berdampak pada menurunnya produksi perikanan laut. Penangkapan perikanan secara terus-menerus tanpa adanya kontrol maka akan mengakibatkan kerusakan ekosistem pada perairan itu sendiri serta keberlanjutannya. Sementara itu, tingkat konsumsi ikan cenderung mengalami peningkatan seiring dengan peningkatan jumlah penduduk tiap tahunnya, tentunya hal ini memerlukan solusi, sebagai upaya untuk memenuhi permintaan konsumsi ikan yang cenderung meningkat dan produksi perikanan laut yang cenderung mengalami penurunan. Perikanan budidaya merupakan salah satu solusi yang bisa dilakukan, mengingat produksinya yang bisa dikontrol baik dengan teknologi inovasi maupun kapasitasnya.

Provinsi Jawa Tengah merupakan provinsi yang memiliki potensi perikanan budidaya yang besar dan dapat meningkatkan kesejahteraan masyarakat. Komoditas unggulan merupakan komoditas perekonomian yang menjadi komoditas dominan atau yang menonjol dari setiap daerah. Dengan diketahuinya komoditas unggulan perikanan budidaya dari setiap kabupaten/kota, DKP Jawa Tengah dan masyarakat dari setiap kabupaten/ kota dapat terus mengembangkannya, sehingga pemerintah daerah melalui DKP Jawa Tengah dan masyarakat daerah dapat mengupayakan atau mendorong komoditas-komoditas tersebut agar dapat menjadi komoditas yang lebih kuat.

Penelitian ini membahas tentang analisis komoditas unggulan di Provinsi Jawa Tengah, yaitu tentang bagaimana karakteristik komoditas-komoditas unggulan di setiap kabuapaten. Metode yang digunakan dalam penelitian ini adalah metode Location Quotient (LQ), Shift Share, dan Indeks Moran. 


\section{TINJAUAN PUSTAKA}

Data yang digunakan dalam penelitian ini merupakan data sekunder yang diperoleh dari buku laporan statistik Dinas Kelautan dan Perikanan Provinsi Jawa Tengah tentang data jumlah produksi setiap komoditas unggulan perikanan budidaya di Jawa Tengah pada tahun 2012 hingga tahun 2016 berdasarkan kabupaten/kota. Menurut DKP Jawa Tengah (2017), ada sembilan komoditas unggulan dari sektor perikanan budidaya dan diharapkan dapat meningkatkan pendapatan nasional terutama Provinsi Jawa Tengah selama lima tahun ke depan, yaitu: ikan bandeng (Chanos chanos), gurame (Osphronemus goramy), mas (Cyprinus carpio), lele (Clarias), nila (Oreochromis niloticus), patin (Pangasius), tawes (Barbonymus gonionotus), udang vaname (Litopenaeus vannamei), dan udang windu (Penaeus monodon).

Komoditas yang memiliki keunggulan memiliki prospek yang lebih baik untuk dikembangkan dan diharapkan dapat mendorong komoditas-komoditas lain untuk berkembang. Metode yang dapat digunakan untuk menganalisis kabupaten/kota mana saja yang berperan sebagai pusat pertumbuhan sembilan komoditas unggulan perikanan budidaya pada penelitian ini adalah metode Location Quotient (LQ) dan metode Shift Share. Dalam penelitian ini juga mengidentifikasi terjadinya autokorelasi spasial menggunakan Indeks Moran.

\subsection{Metode Location Quotient (LQ)}

Menurut Stimson et.al (2006), analisis LQ memiliki tujuan untuk membandingkan besarnya peranan suatu sektor atau industri di suatu daerah terhadap besarnya peranan sektor atau industri tersebut di area referensi (wilayah yang lebih luas). Metode ini juga pernah digunakan oleh Berawi dkk (2016), dengan judul "Menghasilkan konsep alternatif untuk pengembangan proyek jalan tol Trans-Sumatera menggunakan metode location quotient". Penelitian tersebut menghasilkan rute alternatif yang lebih efisien dari 797,29 $\mathrm{km}$ untuk bagian utara jalan tol Trans-Sumatera dengan mempertimbangkan PDRB dan kepadatan penduduk, yaitu terdiri dari Banda Aceh, Sigli, Bireuen, Lhokseumawe, Idirayeuk, Stabat, Medan, Lubukpakam, Limapuluh, dan Raya. Sektor unggulan di kedua provinsi, Sumatera Utara dan Nanggroe Aceh Darussalam (NAD), yaitu NAD terdiri dari Pertambangan di Aceh Utara dan Aceh Timur, serta Industri di Lhoksumawe. Sementara Provinsi Sumatera Utara terdiri dari pertambangan dan pertanian di Langkat, dan indutri di Batubara.

LQ dalam penelitian ini digunakan untuk mengetahui lokasi masing-masing komoditas dan spesialisasi kabupaten/kota di Provinsi Jawa Tengah terhadap komoditas unggulan tersebut.

Menurut Stimson et al (2006), rumus untuk menghitung LQ adalah sebagai berikut:

$$
\mathrm{LQ}=\frac{\left(E_{i, r} / E_{r}\right)}{\left(E_{i, N} / E_{N}\right)}
$$

dengan:

LQ : koefisien Location Quotient

$\mathrm{E}_{\mathrm{i}, \mathrm{r}}$ : jumlah produksi komoditas unggulan ikan i di regional $\mathrm{r}$

$\mathrm{E}_{\mathrm{r}}$ : total produksi seluruh komoditas unggulan di regional $r$ 
$\mathrm{E}_{\mathrm{i}, \mathrm{N}}$ : jumlah produksi komoditas unggulan i di wilayah referensi

$\mathrm{E}_{\mathrm{N}}$ : total produksi seluruh komoditas unggulan di wilayah referensi.

LQ > 1, ikan i di kabupaten $r$ merupakan komoditas unggulan

$\mathrm{LQ} \leq 1$, ikan I di kabupaten $\mathrm{r}$ bukan merupakan komoditas unggulan

Pada penelitian ini, suatu komoditas dikatakan unggul di kabupaten tertentu apabila memiliki rata-rata $L Q>1$ dan standar deviasi $L Q<$ rata-rata $L Q$

\subsection{Metode Shift Share}

Menurut Markusen et al (1991) dalam Stimson et al (2006), teknik yang cepat dan relatif murah untuk menganalisis pertumbuhan dan penurunan regional seiring waktu adalah analisis Shift-Share. Dalam penelitian Tugas Akhir ini, analisis shift share bertujuan untuk menentukan tingkat pertumbuhan produksi suatu komoditas ikan di setiap kabupaten/kota dengan membandingkannya dengan tingkat Provinsi Jawa Tengah. Menurut Dunn (1960) dalam Stimson et al (2006), analisis shift share menggunakan tiga informasi dasar yang saling berhubungan satu sama lain yaitu:

1. Pertumbuhan ekonomi referensi menunjukkan pengaruh pertumbuhan produksi ikan di wilayah referensi terhadap wilayah studi atau disebut dengan istilah national share

2. Pergeseran proporsi (proportional shift) menunjukan perubahan relatif kinerja suatu komoditas di wilayah studi terhadap komoditas yang sama di wilayah referensi

3. Regional shift menunjukkan seberapa jauh daya saing suatu komoditas di wilayah studi dengan perekonomian wilayah referensi.

Adapun rumus persamaan dari analisis Shift Share menurut perloff et al (1960) dalam Stimson et al (2006) adalah sebagai berikut:

$$
\mathrm{G}_{\mathrm{ij}}=\mathrm{y}_{\mathrm{i}, \mathrm{j}, \mathrm{t}}-\mathrm{y}_{\mathrm{i}, \mathrm{j}, 0}=N \mathrm{~S}_{\mathrm{i}, \mathrm{j}}+\mathrm{IM}_{\mathrm{i}, \mathrm{j}}+\mathrm{RS}_{\mathrm{i}, \mathrm{j}}
$$

1. National Shift diperoleh dari rumus:

$$
\mathrm{NS}_{\mathrm{i}, \mathrm{j}}=\mathrm{y}_{\mathrm{i}, \mathrm{j}, 0}\left(\frac{Y_{t}}{Y_{0}}-1\right)
$$

2. Proportional Shift diperoleh dari rumus:

$$
\mathrm{IM}_{\mathrm{i}, \mathrm{j}}=\mathrm{y}_{\mathrm{i}, \mathrm{j}, 0}\left(\frac{Y_{i, t}}{Y_{i, 0}}-\frac{Y_{t}}{Y_{0}}\right)
$$

3. Differential shift diperoleh dari rumus:

$$
\mathrm{RS}_{\mathrm{i}, \mathrm{j}}=\mathrm{y}_{\mathrm{i}, \mathrm{j}, 0}\left(\frac{y_{i, j, t}}{y_{i, j, 0}}-\frac{Y_{i, t}}{Y_{i, 0}}\right)
$$

keterangan:

$\mathrm{G}_{\mathrm{i}, \mathrm{j}} \quad$ : dampak nyata pertumbuhan produksi ikan i di wilayah studi studi $\mathrm{j}$

$\mathrm{y}_{\mathrm{i}, \mathrm{j}, \mathrm{t}} \quad$ : jumlah produksi ikan i di wilayah studi $\mathrm{j}$ pada akhir periode

$\mathrm{y}_{\mathrm{i}, \mathrm{j}, 0} \quad$ : jumlah produksi ikan $\mathrm{i}$ di wilayah studi $\mathrm{j}$ pada awal periode

$\mathrm{NS}_{\mathrm{i}, \mathrm{j}} \quad$ : pengaruh pertumbuhan produksi ikan i di wilayah referensi terhadap sektor $\mathrm{i}$ di wilayah studi $\mathrm{j}$

$\mathrm{IM}_{\mathrm{i}, \mathrm{j}} \quad$ : pergeseran proporsional (tingkat pertumbuhan) ikan i di wilayah studi $\mathrm{j}$

$\mathrm{RS}_{\mathrm{i}, \mathrm{j}} \quad$ : tingkat keunggulan kompetitif (differential shift) ikan i di wilayah studi $\mathrm{j}$ 
$\mathrm{Y}_{\mathrm{t}} \quad$ : total produksi seluruh komoditas di wilayah referensi pada akhir periode

$\mathrm{Y}_{0} \quad$ : total produksi seluruh komoditas i di wilayah referensi pada awal periode

$\mathrm{Y}_{\mathrm{i}, \mathrm{t}} \quad$ : total produksi ikan i di wilayah referensi pada akhir periode

$\mathrm{Y}_{\mathrm{i}, 0} \quad$ : total produksi ikan i di wilayah referensi pada awal periode

Ada dua indikator dari hasil perhitungan shift share analisis sektor atau komoditas unggulan suatu daerah, yaitu:

1. Jika nilai dari komponen pergeseran proporsional dari suatu komoditas $\left(\mathrm{IM}_{\mathrm{i}, \mathrm{j}}\right)>0$, maka komoditas i pada wilayah tersebut tersebut mengalami pertumbuhan yang cepat dan memberikan pengaruh yang positif kepada pertumbuhan wilayah referensi, begitu juga sebaliknya.

2. Jika nilai dari differential shift $\left(\mathrm{RS}_{\mathrm{i}, \mathrm{j}}\right)>0$, maka komoditas i pada wilayah $\mathrm{j}$ memiliki keunggulan kompetitif yang semakin tinggi terhadap wilayah referensi, begitu juga sebaliknya.

Karakteristik pertumbuhan secara sederhana dapat ditentukan dengan analisis gabungan antara metode LQ dan Shift Share. Menurut Akliyah dkk (2017), suatu komoditas dapat dikatakan unggul jika memiliki nilai $L Q \geq 1$ dan nilai $\left(\mathrm{IM}_{\mathrm{i}, \mathrm{j}}+\mathrm{RS}_{\mathrm{i}, \mathrm{j}}\right)$ pada Shift share $\geq 0$, dan komoditas potensial ditandai denngan memiliki nilai $L Q \geq 1$ dan nilai $\left(\mathrm{IM}_{\mathrm{i}, \mathrm{j}}+\mathrm{RS} \mathrm{S}_{\mathrm{i}, \mathrm{j}}\right)$ pada Shift share $<0$.

metode LQ dan Shift share ini juga pernah digunakan oleh Astuti dkk (2017) dalam penelitiannya, dengan judul "Analisis dampak sub sektor unggulan pada sektor basis terhadap pendapatan daerah di Kabupaten Siak, Provinsi Riau”. Hasil penelitian tersebut menunjukkan bahwa berdasarkan analisis LQ menggunakan data Produk Domestik Regional Bruto (PDRB) dari tahun 2009 - 2013 tanpa sektor pertambangan dan penggalian, sektor pertanian menjadi sektor basis dengan perkebunan dan kehutanan sebagai subsektor unggulan. Sedangkan pada sektor pertambangan, minyak dan gas menjadi sub sektor unggulan. Akan tetapi, dari hasil analisis Shift Share menunjukkan bahwa sektor pertanian dengan sub sektor unggulannya memiliki nilai positif, sedangkan sektor pertambangan dengan minyak dan gas sebagai sub sektor unggulan memiliki nilai negatif

\subsection{Identifikasi Autokorelasi Spasial}

Autokorelasi spasial adalah korelasi antar pengamatan pada suatu variabel yang berkaitan dengan lokasi atau dapat dikatakan bahwa autokorelasi spasial adalah analisis penyebaran titik dengan membedakan lokasi dan atributnya. Data spasial adalah data yang memuat adanya informasi lokasi atau geografis dari suatu wilayah. Menurut Wuryandari et al (2014), analisis spasial mengarah pada banyak macam operasi dan konsep termasuk perhitungan sederhana, klasifikasi, penataan, tumpang-susun geometris, dan pemodelan kartografis.

Hal yang sangat penting dalam analisis spasial adalah adanya pembobot atau sering disebut sebagai matriks pembobot spasial. Matriks pembobot spasial digunakan untuk menentukan bobot antar lokasi yang diamati berdasarkan hubungan ketetanggaan antar lokasi. Menurut Lesage (1999), ketetanggaan dapat didefinisikan dalam beberapa cara, yaitu: Rook Contiguity (Persinggungan Sisi), Bishop Contiguity (Persinggungan Sudut), Queen Contiguity (Persinggungan Sisi-Sudut). Pada penelitian ini, matriks pembobot yang digunakan adalah rook contiguity terstandarisasi (standardize contiguity matrix $\boldsymbol{W}$ ), untuk 
mengidentifikasi adanya autokorelasi spasial dapat dilakukan dengan menggunakan Indeks Morans.

Menurut Lesage (1999), perhitungan autokorelasi spasial dapat dilakukan dengan dua cara, yaitu:

1. Indeks Moran dengan matriks pembobot spasial tak terstandarisasi $\mathrm{W}^{*}$

$$
\begin{gathered}
I=\frac{n \sum_{i=1}^{n} \sum_{j=1}^{n} w_{i j}^{*}\left(x_{i}-\bar{x}\right)\left(x_{j}-\bar{x}\right)}{S_{0} \sum_{i=1}^{n}\left(x_{i}-\bar{x}\right)} \\
\text { dengan } S_{0}=\sum_{i=1}^{n} \sum_{j=1}^{n} w_{i j}^{*}
\end{gathered}
$$

2. Indeks Moran dengan matriks pembobot spasial terstandarisasi W

$$
I=\frac{n \sum_{i=1}^{n} \sum_{j=1}^{n} w_{i j}\left(x_{i}-\bar{x}\right)\left(x_{j}-\bar{x}\right)}{\sum_{i=1}^{n}\left(x_{i}-\bar{x}\right)^{2}}
$$

keterangan:

I : Indeks Moran

n : banyaknya lokasi kejadian

$x_{i} \quad$ : nilai pada lokasi i

$x_{j} \quad$ : nilai pada lokasi $\mathrm{j}$

$\bar{x} \quad$ : rata-rata dari jumlah seluruh nilai lokasi penelitian

$w_{i j}^{*} \quad$ : elemen pada pembobot tak terstandarisasi antara daerah $\mathrm{i}$ dan $\mathrm{j}$

$w_{i j} \quad$ : elemen pada pembobot terstandarisasi antara daerah $\mathrm{i}$ dan $\mathrm{j}$

Rentang nilai dari Indeks Moran dalam kasus matriks pembobot spasial terstandarisasi adalah $-1 \leq \mathrm{I} \leq 1$. Nilai $-1 \leq \mathrm{I}<0$ menunjukkan adanya autokorelasi spasial negatif, sedangkan nilai $0<\mathrm{I} \leq 1$ menunjukkan adanya autokorelasi spasial positif. Nilai Indeks Moran bernilai nol $(\mathrm{I}=0)$ mengindikasikan bahwa tidak terdapat autokorelasi spasial.

Menurut Goodchild (1986), untuk mengidentifikasi adanya autokorelasi spasial atau tidak, dilakukan uji signifikansi Indeks Moran.

Hipotesis:

$\mathrm{H}_{0}: I=0$ (Tidak ada autokorelasi spasial antar lokasi)

$\mathrm{H}_{1}: I \neq 0$ (Ada autokorelasi spasial antar lokasi)

Tingkat Signifikansi: $\alpha$

Statistik Uji:

$$
Z_{\text {hitung }}=\frac{I-E(I)}{\sqrt{\operatorname{var}(I)}}
$$

dengan: 


$$
\begin{aligned}
& I \quad=\frac{n \sum_{i=1}^{n} \sum_{j=1}^{n} w_{i j}\left(x_{i}-\bar{x}\right)\left(x_{j}-\bar{x}\right)}{\sum_{i=1}^{n}\left(x_{i}-\bar{x}\right)^{2}} \\
& E(I) \quad=I_{0}=-\frac{1}{n-1} \\
& \operatorname{var}(I)=\frac{n^{2} S_{1}-n S_{2}+3 S_{0}{ }^{2}}{\left(n^{2}-1\right) S_{0}{ }^{2}}-[E(I)]^{2}
\end{aligned}
$$

Keterangan:

$x_{i} \quad=$ Data ke- $i(i=1,2, \ldots, n)$

$x_{j} \quad=$ Data ke- $j(j=1,2, \ldots, n)$

$\bar{x} \quad=$ Rata-rata data

$\operatorname{var}(I)=$ Varian Moran's I

$E(I)=$ Expected value Moran's I

Keputusan: $\mathrm{H}_{0}$ ditolak $\left|Z_{\text {hitung }}\right| \geq Z_{\alpha / 2}$

$$
\begin{array}{ll}
S_{0} & =\sum_{i=1}^{n} \sum_{j=1}^{n} w_{i j} \\
S_{1} & =\frac{1}{2} \sum_{i \neq j}^{n}\left(w_{i j}+w_{j i}\right)^{2} \\
S_{2} & =\sum_{i \neq j}^{n}\left(w_{i 0}+w_{0 i}\right)^{2} \\
w_{i 0} \quad & =\sum_{j=1}^{n} w_{i j} \quad w_{0 i}=\sum_{j=1}^{n} w_{j i}
\end{array}
$$

\section{HASIL DAN PEMBAHASAN}

Analisis Location Quotient ddigunakan untuk mengetahui kabupaten mana saja yang menjadi wilayah pertumbuhan setiap komoditas unggulan perikanan budidaya di Provinsi Jawa Tengah. Jika nilai rata-rata LQ > 1 dan standar deviasi $L Q<$ rata-rata LQ maka komoditas tersebut unggul di kabupaten tersebut. Berdasarkan hasil analisis, maka diperoleh hasil bahwa ikan bandeng lebih unggul di Kabupaten Pemalang dengan rata-rata $\mathrm{LQ}=3,11790$ dan standar deviasi $\mathrm{LQ}=0,233922$, ikan gurame lebih unggul di Kabupaten Banyumas dengan rata-rata $\mathrm{LQ}=11,252023$ dan standar deviasi $\mathrm{LQ}=2,163283$, ikan mas lebih unggul di Kabupaten Temanggung dengan rata-rata $L Q=13,724865$ dan standar deviasi $L Q=3,745627$. Ikan lele dan ikan nila merupakan komoditas yang dibudidayakan di semua kabupaten Provinsi Jawa Tengah, namun dari hasil analisis diperoleh bahwa ikan lele lebih unggul di Kabupaten Blora dengan rata-rata LQ = 2,979573 dan standar deviasi $\mathrm{LQ}=0,391870$, sedangkan ikan nila lebih unggul di Kabupaten Wonogiri dengan rata-rata $\mathrm{LQ}=3,889201$ dan standar deviasi LQ sebesar 0,568736. Selain itu, ikan patin lebih unggul di Kabupaten Purbalingga dengan rata-rata LQ $=8,168610$ dan standar deviasi LQ $=6,204588$, dan ikan tawes lebih unggul di Kabupaten Banyumas dengan rata-rata LQ = 14,029287 dan standar deviasi LQ $=5,498703$. Selain ikan, udang vaname dan udang windu juga merupakan komoditas unggulan perikanan budidaya Provinsi Jawa Tengah. Berdasarkan hasil analisis Location Quotient, udang vaname lebih unggul di kabupaten Purworejo dengan rata-rata $\mathrm{LQ}=11,670500$ dan standar deviasi $\mathrm{LQ}=8,319955$, dan udang windu lebih unggul di Kabupaten Rembang dengan rata-rata LQ $=6,147305$ dan standar deviasi LQ = 2,575621.

Analisis Shift Share bertujuan untuk mengidentifikkasi tingkat pertumbuhan dan tingkat kompetitif setiap komoditas dari setiap kabupaten di Provinsi Jawa Tengah. Berdasarkan hasil analisis, diperoleh bahwa setiap kabupaten memiliki tingkat pertumbuhan dan tingkat kompetitif yang berbeda-beda. Identifkasi karakteristik pertumbuhan komoditas unggulan secara sederhana bisa didapatkan dari analisis LQ dan Shift Share. Suatu komoditas disebut unggul di suatu kabupaten apabila memiliki rata-rata LQ $\geq 1$ dan nilai $\left(\mathrm{IM}_{\mathrm{i}, \mathrm{j}}+\mathrm{RS}_{\mathrm{i}, \mathrm{j}}\right)$ pada Shift share $\geq 0$. Apabila suatu komoditas memiliki 
rata-rata LQ LQ $\geq 1$ dan nilai $\left(\mathrm{IM}_{\mathrm{i}, \mathrm{j}}+\mathrm{RS}_{\mathrm{i}, \mathrm{j}}\right)$ pada Shift share $<0$ di suatu kabupaten, maka komoditas tersebut merupakan komoditas potensial. Hasil analisis penggabungan dua jenis analisis ini dapat dilihat pada Tabel 1 berikut:

Tabel 1. Karakteristik Pertumbuhan Komoditas Unggulan di Jawa Tengah

\begin{tabular}{|c|c|c|}
\hline \multirow{2}{*}{ Kabupaten/kota } & \multicolumn{2}{|c|}{ Komoditas } \\
\hline & Unggulan & Potensial \\
\hline Kabupaten Cilacap & Mas, Patin, Unggul & $\begin{array}{c}\text { Gurame, Tawes, Udang } \\
\text { Windu }\end{array}$ \\
\hline Kabupaten Banyumas & Gurame & Mas, Tawes \\
\hline $\begin{array}{c}\text { Kabupaten } \\
\text { Purbalingga }\end{array}$ & & Gurame, Lele, Patin, Tawes \\
\hline $\begin{array}{c}\text { Kabupaten } \\
\text { Banjarnegara }\end{array}$ & Gurame, lele & Mas, Patin, Tawes \\
\hline Kabupaten Kebumen & & Gurame, Lele \\
\hline Kabupaten Purworejo & Udang Vaname & Gurame, Tawes \\
\hline Kabupaten Wonosobo & & Nila \\
\hline Kabupaten Magelang & $\begin{array}{c}\text { Mas, Lele, Nila, Patin, } \\
\text { Tawes }\end{array}$ & \\
\hline Kabupaten Boyolali & & Lele \\
\hline Kabupaten Klaten & & Nila \\
\hline Kabupaten Sukoharjo & Lele, Patin & Nila \\
\hline Kabupaten Wonogiri & Patin & Nila \\
\hline $\begin{array}{c}\text { Kabupaten } \\
\text { Karanganyar }\end{array}$ & Lele, Patin & \\
\hline Kabupaten Sragen & Mas, Patin & Nila \\
\hline Kabupaten Grobogan & Gurame, lele, Patin, Tawes & \\
\hline Kabupaten Blora & $\begin{array}{l}\text { Lele } \\
\end{array}$ & \\
\hline Kabupaten Rembang & $\begin{array}{c}\text { Udang Vaname, Udang } \\
\text { Windu }\end{array}$ & \\
\hline Kabupaten Pati & & Bandeng, Udang Windu \\
\hline Kabupaten Kudus & Lele & Mas \\
\hline Kabupaten Jepara & Bandeng, Udang Windu & \\
\hline Kabupaten Demak & & Bandeng, Lele \\
\hline Kabupaten Semarang & Lele & Mas \\
\hline $\begin{array}{c}\text { Kabupaten } \\
\text { Temanggung }\end{array}$ & Mas, Nila & \\
\hline Kabupaten Kendal & Bandeng, Udang Vaname & \\
\hline Kabupaten Batang & Bandeng & Patin \\
\hline $\begin{array}{l}\text { Kabupaten } \\
\text { Pekalongan }\end{array}$ & Bandeng & Tawes \\
\hline Kabupaten Pemalang & Bandeng, Udang Vaname & \\
\hline Kabupaten Tegal & Bandeng, Lele & \\
\hline Kabupaten Brebes & Udang Vaname & Bandeng, Udang Windu \\
\hline Kota Magelang & Nila & Mas, Lele \\
\hline Kota Surakarta & Lele & \\
\hline Kota Salatiga & & Lele \\
\hline Kota Semarang & Bandeng & \\
\hline
\end{tabular}




\begin{tabular}{|c|c|c|}
\hline \multirow{2}{*}{ Kabupaten/kota } & \multicolumn{2}{|c|}{ Komoditas } \\
\cline { 2 - 3 } & Unggulan & Potensial \\
\hline Kota Pekalongan & Udang Vaname & Bandeng, Udang Windu \\
\hline Kota Tegal & & Bandeng \\
\hline
\end{tabular}

Analisis autokorelasi spasial bertujuan untuk mengidentifikasi apakah produksi perikanan budidaya antar kabupaten di Provinsi Jawa Tengah saling berkorelasi atau tidak. Metode analisis yang dapat digunakan dalam menganalisis autokorelasi spasial adalah Indeks Moran. Hasil perhitungan Indeks Moran adalah sebagai berikut:

$$
I=\frac{n \sum_{i=1}^{n} \sum_{j=1}^{n} w_{i j}\left(x_{i}-\bar{x}\right)\left(x_{j}-\bar{x}\right)}{\sum_{i=1}^{n}\left(x_{i}-\bar{x}\right)^{2}}=\frac{-589024507,57}{4265991517,04}=-0,1381
$$

i. Hipotesis:

$\mathrm{H}_{0}: I=0$ (Tidak ada autokorelasi spasial antar lokasi)

$\mathrm{H}_{1}: I \neq 0$ (Ada autokorelasi spasial antar lokasi)

ii. Taraf signifikansi: $\alpha=5 \%$

iii. Statistik uji:

$$
Z_{\text {hitung }}=\frac{I-E(I)}{\sqrt{\operatorname{var}(I)}}
$$

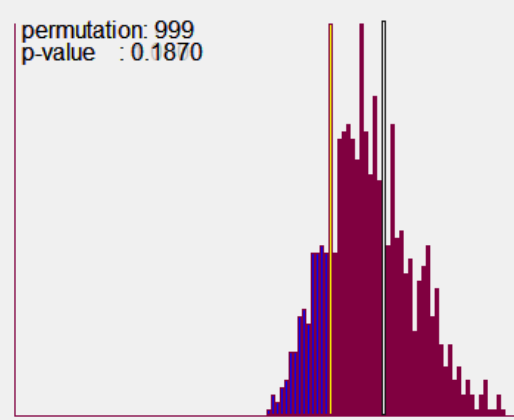

l:-0.1381 E[ll:-0.0294 Mean:-0.0302 Sd:0.1184

Gambar 1 Output Analisis Software OpenGeoDa

dimana:

$$
\begin{aligned}
& I=-0,1381 \\
& \mathrm{I}_{0}=\mathrm{E}(I)=-0,0294 \\
& \mathrm{Sd}=0,1184 \text { maka } \operatorname{Var}(I)=0,01402
\end{aligned}
$$

Sehingga:

$$
Z_{\text {hitung }}=\frac{-0,1381-(-0,0294)}{\sqrt{0,01402}}=-0,918
$$

iv. Kriteria uji:

$\mathrm{H}_{0}$ ditolak jika $\left|Z_{\text {hitung }}\right| \geq Z_{\alpha / 2}$ atau $\mathrm{p}$-value $\leq \alpha$

v. Kesimpulan 
$\left|Z_{\text {hitung }}\right|<Z_{\alpha / 2}=0,918<1,96$ dan p-value $>\alpha=0,1870>0,05$ maka $\mathrm{H}_{0}$ diterima. Dari hasil perhitungan dapat disimpulkan bahwa pada taraf signifikansi 5\% tidak terdapat autokorelasi spasial terhadap jumlah produksi perikanan budidaya di Jawa Tengah pada tahun 2016. Nilai Indeks Moran sebesar -0,1381 berada pada rentang $-1 \leq I<0$ dan $I<\mathrm{I}_{0}=-0,1381<-0,0294$ menunjukkan adanya autokorelasi negatif, namun korelasinya dapat dikatakan lemah karena mendekati nol, sehingga disimpulkan bahwa antar kabupaten satu dengan yang lainnya tidak memiliki kemiripan nilai atau mengindikasikan bahwa jumlah produksi perikanan budidaya antar kabupaten di Jawa Tengah tidak saling berkorelasi.

\section{KESIMPULAN}

Berdasarkan pada hasil analisis penelitian yang telah dilakukan, dapat disimpulkan beberapa hal sebagai berikut:

1. Wilayah yang menjadi pusat pertumbuhan dari setiap komoditas unggulan perikanan budidaya di Provinsi Jawa Tengah berbeda-beda.

2. Kabupaten Cilacap menjadi kabupaten yang paling potensial dalam produksi komoditas unggulan perikanan budidaya dibandingkan dengan 34 kabupaten lainnya .

3. Berdasarkan hasil analisis autokorelasi spasial memberikan hasil sebagai berikut:

a. Perhitungan, nilai Indeks Moran I = -0,1381. Nilai Indeks Moran ini berada pada rentang

$-1<I \leq 0$ sehingga menunjukkan adanya autokorelasi spasial negatif namun korelasinya dapat dikatakan lemah karena mendekati nol, sehingga menyebabkan tidak adanya autokorelasi spasial pada pengujian signifikansi Indeks Moran.

b. pengujian signifikansi Indeks Moran dengan taraf signifikansi 5\% diperoleh hasil $\left|Z_{\text {hitung }}\right|<Z_{\alpha / 2}=0,918<1,96$ dan p-value $>\alpha=0,1870>0,05$, sehingga dapat disimpulkan bahwa antar kabupaten satu dengan yang lainnya tidak memiliki kemiripan nilai atau mengindikasikan bahwa jumlah produksi perikanan budidaya antar kabupaten di Jawa Tengah tidak saling berkorelasi.

\section{DAFTAR PUSTAKA}

Akliyah, L. S., Asyiawati, Y., Putri, S. E. 2014. Identifikasi Komoditas Unggulan Perikanan Tangkap di Kawasan Minapolitan Kabupaten Indramayu. Prosiding SnaPP2014 Sains, Teknologi, dan Kesehatan.

Anselin, L dkk. 2010. Perspectives On Spatial Data Analysis. Verlag Berlin Heidelberg: Springer.

Astuti, P., Nugraha, I., Abdillah, F. 2017. Impact analysis of leading sub sector on basic sector to regional income in Siak Regency, Riau Province. IOP Publishing 309 (2018).

Basuki, A.T. 2009. Analisis Potensi Unggulan Kabupaten Kepulauan Yapen dalam Menopang Pembangunan Papua Tahun 2004-2008. UNISIA. Vol XXXII (71): 5-19.

Berawi, M.A., Zagloel,T.Y., Miraj, P., Mulyanto, H. 2016. Producing alternative concept for the Trans-Sumatera toll road project development using location quotient method. Procedia Engineering 171 (2017): 265-273.

Dinas Kelautan dan Perikanan (DKP) Provinsi Jawa Tengah. 2014. Profil Perikanan Budidaya. (Diakses Januari 2018).

Dinas Kelautan dan Perikanan (DKP). 2013. Data Produksi Perikanan Budidaya Tahun 2012. Jawa Tengah: Dinas Kelautan dan Perikanan. 
Dinas Kelautan dan Perikanan (DKP). 2014. Data Produksi Perikanan Budidaya Tahun 2013. Jawa Tengah: Dinas Kelautan dan Perikanan.

Dinas Kelautan dan Perikanan (DKP). 2015. Data Produksi Perikanan Budidaya Tahun 2014. Jawa Tengah: Dinas Kelautan dan Perikanan.

Dinas Kelautan dan Perikanan (DKP). 2016. Data Produksi Perikanan Budidaya Tahun 2015. Jawa Tengah: Dinas Kelautan dan Perikanan.

Dinas Kelautan dan Perikanan (DKP). 2017. Data Produksi Perikanan Budidaya Tahun 2016. Jawa Tengah: Dinas Kelautan dan Perikanan.

Diputra, T. F., Sadik, K., and Angraini, Y. 2012. Pemodelan Data Panel Spasial dengan Dimensi Ruang dan Waktu. Forum Statistika dan Komputasi : Indonesian Journal of Statistics. Vol XVII (1): 6-14.

Goodchild, M. F. 1986. Spatial Autocorrelation. Norwich: Geo Books.

Hariyanti, D., Utha, M. A. 2016. Analysis of Determinants Sectors Regional Development at 33 Provinces in Indonesia. OIDA International Journal of Sustainable Development. Vol IX (3): 11-32.

Kementrian Kelautan dan Perikanan Republik Indonesia. 2014. Profil Indonesia. Jakarta: Kementrian Kelautan dan Perikanan RI.

Lesage, J.P. 1999. The Theory and Practice of Spatial Econometrics. University of Toledo: Department of Economics.

Stimson, R.J dkk. 2006. Regional Economic Development. Verlag Berlin Heidelberg: Springer.

Tarigan, R. 2005. Ekonomi Regional. Jakarta: PT Bumi Aksara.

Wuryandari, T., Hoyyi, A., Kusumawardani, D.S., dan Rahmawati, D. 2014. Identifikasi Autokorelasi Spasial Pada Jumlah Pengangguran di Jawa Tengah Menggunakan Indeks Moran. Media Statistika. Vol VII (1): 1-10. 